\title{
Climatic Characteristics of Hubei Tobacco Area and Its Influence on the Quality of Upper Leaves
}

\section{Wan Zhao ${ }^{*}$, Guangwei Sun ${ }^{2 *}$, Jingguo Sun ${ }^{2}$, Ji Feng², Shouwen Chen ${ }^{1}$, Zhenguo Chen ${ }^{2 \#,}$ Yong Yang1\#}

\author{
${ }^{1}$ State Key Laboratory of Biocatalysis and Enzyme Engineering, Hubei University, Wuhan, China \\ ${ }^{2}$ Tobacco Research Institute of Hubei Province, Wuhan, China \\ Email: "yangyong@hubu.edu.cn, "hbskys1@163.com
}

How to cite this paper: Zhao, W., Sun, G.W., Sun, J.G., Feng, J., Chen, S.W., Chen, Z.G. and Yang, Y. (2021) Climatic Characteristics of Hubei Tobacco Area and Its Influence on the Quality of Upper Leaves. Agricultural Sciences, 12, 863-874. https://doi.org/10.4236/as.2021.128055

Received: June 10, 2021

Accepted: August 17, 2021

Published: August 20, 2021

Copyright $\odot 2021$ by author(s) and Scientific Research Publishing Inc. This work is licensed under the Creative Commons Attribution International License (CC BY 4.0).

http://creativecommons.org/licenses/by/4.0/

\begin{abstract}
In order to provide a more suitable environment for tobacco leaf growth, this study collected meteorological information and tobacco leaf quality information from the main tobacco-producing counties in the province and conducted relevant analysis to find out the main meteorological factors affecting the growth, development, yield, and quality of upper tobacco leaves. Clarify the suitable climatic conditions for the growth and development of the upper leaves, and clarify the influence of various meteorological factors on the quality of the upper leaves. The results showed that the nicotine and total nitrogen content of the upper leaves were significantly positively correlated with the average daily temperature during the maturity period, and negatively correlated with the rainfall during the maturity period; the rainfall in July was significantly positively correlated with the upper leaf clutter score, which was sufficient in the mature period. Moisture conditions are conducive to alleviating the upper leaf clutter; the number of sunshine hours in August is the main factor affecting the content of aroma substances in the upper leaves, and it is also significantly positively correlated with the content of aroma substances.
\end{abstract}

\section{Keywords}

Climatic Characteristics, Quality of Flue-Cured Tobacco, Upper Leaf Tobacco

\section{Introduction}

Tobacco is a commercial cash crop widely grown in the world, and it is very sensitive to the environment [1]. The quality of tobacco leaves is restricted by many

${ }^{\star}$ Authors contribute equally to present work.

"Corresponding authors. 
factors, the most important of which are genetic factors, ecological environment and cultivation techniques [2]-[10]. A large number of studies have shown that the quality of flue-cured tobacco is the result of the combined effects of genetic factors, ecological environment and cultivation techniques [11] [12] [12]. The genotype is the internal cause of genetic expression, and the production technology can be artificially controlled [9]. The ecological factors as external factors are the basic conditions for the growth of tobacco plants in the field, the yield and value of tobacco leaves, the chemical composition, the content of aroma substances, and the quality of tobacco leaves. The ecological environment affects the quality of tobacco leaves, and the climatic factor is one of the important ecological environmental factors that cause the regional distribution of flue-cured tobacco content and yield. The main climatic factors that directly affect the yield and quality of flue-cured tobacco are light, temperature, and precipitation [8] [14] [15]. Ecological factors such as temperature, sunshine hours, precipitation, and other factors in the growth period of tobacco fields will affect the quality of tobacco leaves, which make the quality and flavor of tobacco leaves obvious and irreplaceable regional characteristics and ecological advantages [16] [17] [18]. The upper leaves of flue-cured tobacco include the upper two sheds and the 6-7 tobacco leaves at the top, accounting for $30 \%-45 \%$ of the total output per plant, and occupies a very important position in the production of tobacco raw materials [3] [4]. The predecessors have carried out the influence of climate factors on the quality of flue-cured tobacco in many tobacco areas, such as Xingshan tobacco area [19], Enshi tobacco area [20] and so on. However, for the main tobacco-producing areas in Hubei province, there is no systematic exploration of the effects of climatic factors during the growth period of each field on the quality of flue-cured tobacco upper tobacco. Therefore, this study collected meteorological information and flue-cured tobacco upper leaf quality information from the main tobacco-producing counties in the province. Analyze and find out the main meteorological factors affecting the growth and development, production and quality of upper tobacco leaves, in order to provide references for the production and cultivation of high-quality flue-cured tobacco in Hubei Province.

\section{Materials and Methods}

\subsection{Material}

\subsubsection{Meteorological Data Sources}

Collect the meteorological data from May to September during the growth period of flue-cured tobacco in various tobacco-producing counties in Hubei province (Hefeng, Xuan'en, Enshi, Lichuan, Badong, Zigui, Zhuxi, Zhushan, Baokang, and Fangxian) during the past five years. Provided by Hubei Meteorological Bureau, each observation point is selected by professionals from the $\mathrm{Hu}-$ bei Meteorological Bureau. The meteorological data is highly representative and can more accurately reflect the climate change in the monitoring area. Accord- 
ing to meteorological data and combined with the season of flue-cured tobacco planting in Hubei, the growth period (May-September) of flue-cured tobacco field (May-September), which has a greater impact on the growth and quality of tobacco leaves, is selected for analysis and research.

\subsubsection{Smoke Sample Collection}

The test flue-cured tobacco variety is YY87. In 2016, the five-point sampling method was adopted in the above-mentioned main tobacco-producing areas. Three parallel samples were set after mixing. Full-time students selected "B2F" tobacco leaf samples for inspection according to the national standard quality of Flue-cured Tobacco (GB2635-92 Flue-cured Tobacco Standard).

\subsection{Method}

The agronomic traits such as leaf length, leaf width, leaf area, etc. were determined uniformly at 8, 14 and 20 every day, and samples were taken for chemical composition analysis and volume evaluation.

\subsection{Data Processing}

Use SPSS 19.0 statistical software and Excel 2007 and other software to perform statistical analysis on the data.

\section{Results and Analysis}

\subsection{Analysis of Climatic Characteristics of the Main Flue-Cured Tobacco Producing Areas in Hubei Province}

The Conditions of Light, Temperature and Water during the Growth Period in the Main Producing Areas of Flue-Cured Tobacco

The main meteorological data of the 11 counties during the field growth period from 2011 to 2015 are shown in Figure 1. It can be seen that the average temperature of the 11 counties exceeds $20^{\circ} \mathrm{C}$ from July to August, which is significantly higher than other months in the growth period. The temperature in the 11 production areas was the highest in July (Figure 1(a)); at the same time, the rainfall in the 11 main flue-cured tobacco producing areas increased significantly in September, except for most of them, the rainfall increased slightly in July (Figure 1(b)); the sunshine hours in July and August were significantly higher than other months, with the lowest sunshine hours reaching $225.57 \mathrm{~h}$, up to 285.69 h (Figure 1(c)).

The cluster analysis of the main climatic factors during the field growth period in 11 counties shows that the climatic conditions of the tobacco areas in our province are mainly divided into two categories. Nanzhang, Baokang, Fangxian, Zhushan, Zhuxi, Badong, and Zigui are grouped into one category, Enshi, Xuan'en, Lichuan, and Hefeng are grouped into one category. The first category is mainly tobacco areas in northwest Hubei, and the second category is mainly Tobacco area in southwest Hubei. By analyzing its climatic factors, it can be seen that the average daily high of $0.65^{\circ} \mathrm{C}$ from May to September in southwest Hubei 

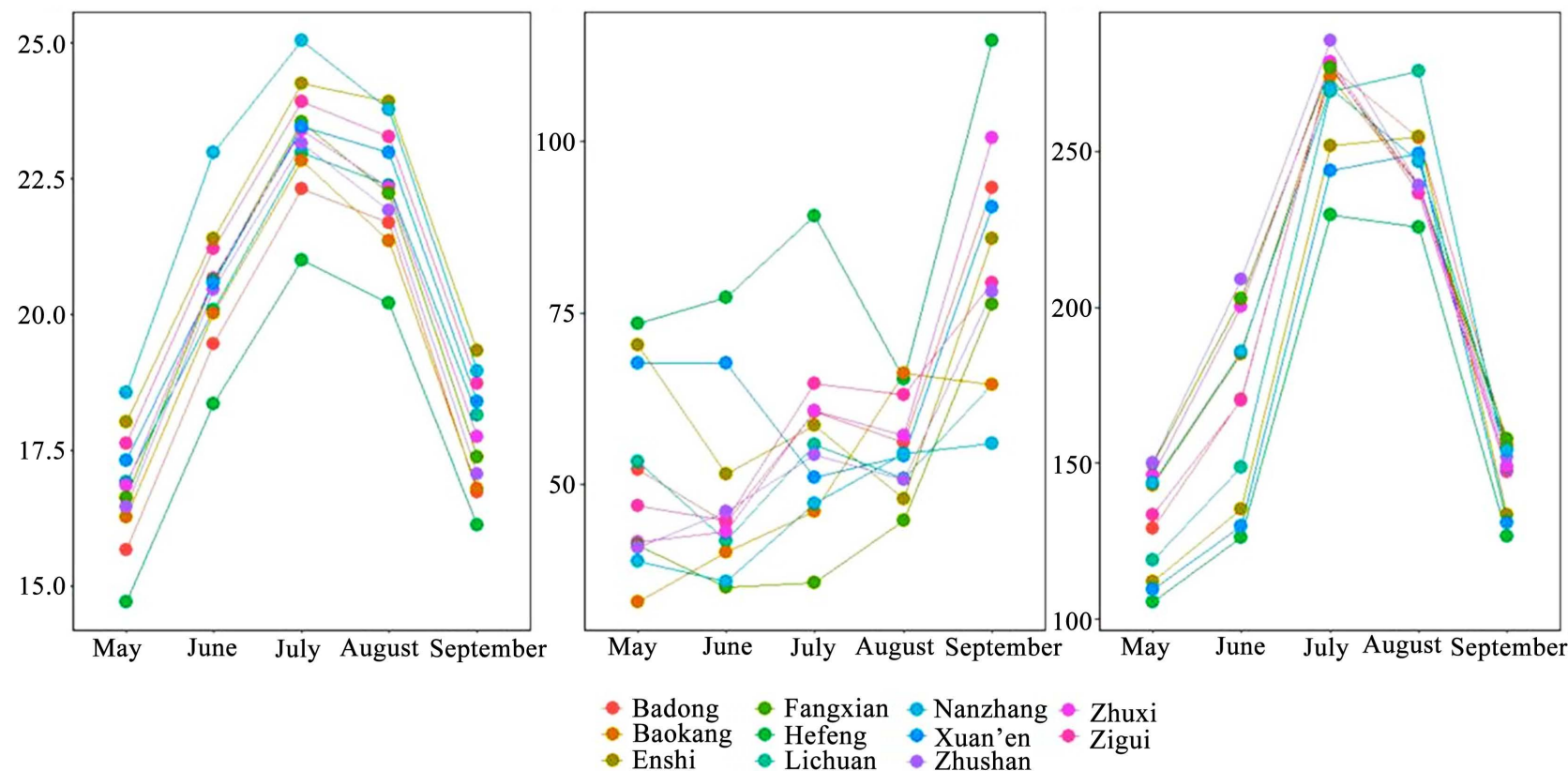

(a)

(b)

(c)

Figure 1. Meteorological conditions during the growth period of flue-cured tobacco in various regions from 2011 to 2015 ((a): Average temperature during growth period of flue-cured tobacco in various regions; (b): Average rainfall during growth period of flue-cured tobacco; (c): Average sunshine duration during growth period of flue-cured tobacco in various regions).

and northwest Hubei. During the mature period of upper tobacco leaves, the daily average temperature in southwest Hubei is significantly higher than that in northwest Hubei, which is more conducive to the maturity of upper tobacco leaves. During the growth period of flue-cured tobacco fields, the total rainfall in southwest Hubei was $35.17 \mathrm{~mm}$ higher than that in northwest Hubei. From the distribution of rainfall, the rainfall in the tobacco planting areas in southwest Hubei showed a trend of first decrease and then increase, while the rainfall in the tobacco planting areas in northwest Hubei The rainfall is on the rise. From the analysis of rainfall data, the rainfall in southwest Hubei from May to July is higher than that in northwest Hubei, and the rainfall in southwest Hubei in May is $22.58 \mathrm{~mm}$ higher than that in northwest Hubei; observing the change of the sunshine hours from May to September, the sunshine hours showed a trend of increasing first and then decreasing. The sunshine hours in the southwest of Hubei reached the maximum in August, and the sunshine hours in the northwest of Hubei reached the maximum in July. From the data, the total sunshine hours during the growth period of flue-cured tobacco in the field show that the northwestern Hubei tobacco area is 120.92 hours longer than the southwestern Hubei tobacco area. The sunshine hours in the northwestern Hubei from May to July are significantly higher than southwestern Hubei. It can be seen that high average temperature, high average rainfall and long sunshine duration are more conducive to the ripening of the upper tobacco leaves in the tobacco area of $\mathrm{Hu}$ bei Province. 


\subsection{The Relationship between Conventional Chemical Composition, Sensory Quality, Aroma Substance Content of Upper Leaves and Meteorological Conditions during the Growth Period}

\subsubsection{Analysis of the Chemical Composition of Upper Tobacco Leaves and Meteorological Conditions during the Growth Period}

Analysis of the chemical composition of the upper tobacco leaves and the meteorological conditions during the growth period, the results are shown in Table 1.

It can be seen that the main meteorological factor affecting the nicotine content is the rainfall during the growth period. The nicotine and total nitrogen content are significantly positively correlated with the sunshine hours in September, and the nicotine is significantly correlated with the rainfall in September. Negative correlation, which affects the coordination of sugar-to-base ratio and nitrogen-base ratio; potassium ion content is significantly positively correlated with the average temperature throughout the growth period.

Table 1. Correlation analysis between the conventional chemical composition of upper leaves and the meteorological conditions in May-September from 2011 to 2015.

\begin{tabular}{|c|c|c|c|c|c|c|c|c|c|}
\hline & & Nicotine & $\begin{array}{l}\text { Total } \\
\text { sugar }\end{array}$ & chlorine & Potassium & $\begin{array}{c}\text { Total } \\
\text { nitrogen }\end{array}$ & $\begin{array}{l}\text { Sugar-base } \\
\text { ratio }\end{array}$ & $\begin{array}{c}\text { Nitrogen } \\
\text { to alkali ratio }\end{array}$ & $\begin{array}{c}\text { Potassium } \\
\text { Chlorine Ratio }\end{array}$ \\
\hline \multirow{3}{*}{ May } & average temperature $\left({ }^{\circ} \mathrm{C}\right)$ & 0.27 & -0.01 & 0.05 & $0.74^{*}$ & 0.11 & -0.17 & -0.17 & 0.24 \\
\hline & rainfall $(\mathrm{mm})$ & $-0.64^{*}$ & 0.25 & 0 & -0.17 & -0.34 & 0.48 & 0.41 & -0.02 \\
\hline & Sunshine hours (h) & 0.37 & -0.22 & -0.05 & 0.23 & 0.34 & -0.25 & -0.14 & 0.17 \\
\hline \multirow{3}{*}{ June } & average temperature $\left({ }^{\circ} \mathrm{C}\right)$ & 0.33 & -0.09 & 0.1 & $0.66^{*}$ & 0.29 & -0.21 & -0.13 & 0.19 \\
\hline & rainfall $(\mathrm{mm})$ & $-0.52^{*}$ & 0.02 & -0.05 & -0.32 & -0.34 & 0.26 & 0.32 & -0.1 \\
\hline & Sunshine hours (h) & 0.24 & -0.16 & -0.16 & 0.22 & 0.31 & -0.13 & -0.03 & 0.29 \\
\hline \multirow{3}{*}{ July } & average temperature $\left({ }^{\circ} \mathrm{C}\right)$ & 0.3 & -0.14 & 0.11 & $0.68^{*}$ & 0.18 & -0.21 & -0.16 & 0.19 \\
\hline & rainfall $(\mathrm{mm})$ & $-0.59^{*}$ & $0.62^{*}$ & -0.28 & -0.21 & -0.12 & $0.65^{*}$ & $0.55^{*}$ & 0.19 \\
\hline & Sunshine hours (h) & 0.39 & 0.08 & -0.29 & $0.58^{*}$ & 0.24 & -0.11 & -0.22 & 0.4 \\
\hline \multirow{3}{*}{ August } & average temperature $\left({ }^{\circ} \mathrm{C}\right)$ & 0.16 & -0.02 & 0.05 & $0.78^{*}$ & 0.11 & -0.06 & -0.07 & 0.27 \\
\hline & rainfall $(\mathrm{mm})$ & 0.12 & 0.17 & 0.13 & -0.33 & 0.05 & -0.11 & -0.08 & -0.3 \\
\hline & Sunshine hours (h) & 0.29 & 0.05 & -0.2 & 0.33 & 0.01 & -0.1 & -0.3 & 0.22 \\
\hline \multirow{3}{*}{ September } & average temperature $\left({ }^{\circ} \mathrm{C}\right)$ & 0.08 & 0.01 & -0.02 & $0.78^{*}$ & 0 & 0.01 & -0.04 & 0.32 \\
\hline & rainfall $(\mathrm{mm})$ & $-0.77^{*}$ & 0.23 & -0.19 & -0.34 & -0.16 & $0.59^{*}$ & $0.70^{*}$ & 0.16 \\
\hline & Sunshine hours (h) & $0.68^{*}$ & -0.12 & 0.02 & 0.16 & $0.54^{*}$ & -0.42 & -0.39 & -0.04 \\
\hline
\end{tabular}

$\mathrm{r}>0$ represents a positive correlation between two variables, and $\mathrm{r}<0$ represents a negative correlation between two variables. When $|\mathrm{r}|$ is greater than or equal to 0.8 , it can be considered that the two variables are highly correlated; when $|\mathrm{r}|$ is greater than or equal to 0.5 and less than 0.8 , it can be considered that the two variables are moderately correlated; when $|\mathrm{r}|$ is greater than or equal to 0.3 and less than 0.5 , it can be considered that the two variables are lowly correlated; $|\mathrm{r}|$ less than 0.3 indicates that the correlation is very weak and basically irrelevant. ${ }^{*}$ Indicates that the difference is at a significant level $(\mathrm{P}<0.05)$, ** indicates that the difference is at a very significant level $(\mathrm{P}<0.01)$, the same below. 


\subsubsection{Analysis of Sensory Quality, Aroma Substances and Meteorological Conditions during Growth Period of Upper Tobacco Leaves}

The correlation analysis between the average B2F sensory quality evaluation and the meteorological conditions during the growth period in the past five years was carried out. The results are shown in Table 2. It can be seen that the rainfall in July is a key factor affecting the upper leaf clutter.

At the same time, the correlation analysis between B2F neutral aroma substance content and meteorological conditions during the growth period in the past five years was carried out. The results are shown in Table 3. It can be seen that the sunshine hours in August have the greatest impact on aroma components. It is significantly positively correlated with the aroma content of the upper leaves, such as Macrostigmatrienone, 3-hydroxy- $\beta$-dihydrodamascenone, neophytadiene, dihydrokiwifruit lactone, 4-(2, 6, 6-trimethyl-1, 3-cyclohexadien-1yl)-2-butanone, eduran, furfural, furfuryl alcohol, 5-methylfurfuryl alcohol and so on. The number of sunshine hours in August is the main factor affecting the aroma content of the upper leaves.

\subsection{The Relationship between Upper Leaf Agronomic Traits and Meteorological Conditions}

Because the climatic factors of light and warm water in Lichuan were close to the average values of 11 flue-cured tobacco production areas, three test sites were set

Table 2. Correlation analysis between the sensory evaluation of upper leaves and the meteorological conditions in May-September from 2011 to 2015 .

\begin{tabular}{|c|c|c|c|c|c|c|c|}
\hline & & quality of aroma & volume of aroma & Miscellaneous gas & Irritation & Aftertaste & $\begin{array}{l}\text { Total } \\
\text { score }\end{array}$ \\
\hline & average temperature $\left({ }^{\circ} \mathrm{C}\right)$ & -0.27 & 0 & 0.09 & -0.19 & -0.16 & -0.21 \\
\hline \multirow[t]{3}{*}{ May } & rainfall $(\mathrm{mm})$ & 0.05 & 0.1 & -0.49 & 0.06 & -0.2 & 0 \\
\hline & sunshine hours (h) & -0.19 & -0.16 & 0.43 & 0.06 & 0.13 & -0.05 \\
\hline & average temperature $\left({ }^{\circ} \mathrm{C}\right)$ & -0.29 & -0.01 & 0.1 & -0.04 & -0.08 & -0.17 \\
\hline \multirow[t]{3}{*}{ June } & rainfall $(\mathrm{mm})$ & 0.29 & 0.32 & -0.49 & 0.07 & 0.08 & 0.22 \\
\hline & sunshine hours (h) & -0.25 & -0.21 & 0.39 & 0.05 & 0.1 & -0.1 \\
\hline & average temperature $\left({ }^{\circ} \mathrm{C}\right)$ & -0.3 & -0.01 & 0.2 & -0.09 & -0.14 & -0.18 \\
\hline \multirow[t]{3}{*}{ July } & rainfall (mm) & -0.06 & -0.18 & $0.73^{*}$ & 0.13 & -0.18 & -0.14 \\
\hline & sunshine hours (h) & -0.46 & -0.48 & 0.38 & -0.23 & -0.2 & -0.4 \\
\hline & average temperature $\left({ }^{\circ} \mathrm{C}\right)$ & -0.4 & -0.1 & 0.05 & -0.17 & -0.32 & -0.31 \\
\hline \multirow[t]{3}{*}{ August } & rainfall $(\mathrm{mm})$ & 0.43 & 0.23 & -0.11 & 0.16 & 0.15 & 0.3 \\
\hline & sunshine hours (h) & -0.25 & -0.27 & 0.04 & -0.49 & -0.2 & -0.37 \\
\hline & average temperature $\left({ }^{\circ} \mathrm{C}\right)$ & -0.31 & -0.04 & -0.06 & -0.23 & -0.27 & -0.28 \\
\hline \multirow[t]{2}{*}{ September } & rainfall $(\mathrm{mm})$ & -0.01 & 0.09 & -0.35 & 0.34 & -0.07 & 0.12 \\
\hline & sunshine hours (h) & -0.24 & -0.32 & 0.49 & -0.06 & 0.01 & -0.18 \\
\hline
\end{tabular}


Table 3. Correlation analysis of aroma components and meteorological factors in upper leaves from 2011 to 2015.

\begin{tabular}{|c|c|c|c|c|c|c|c|c|c|}
\hline \multirow[b]{2}{*}{ Aroma substance } & \multicolumn{3}{|c|}{ July } & \multicolumn{3}{|c|}{ August } & \multicolumn{3}{|c|}{ September } \\
\hline & $\begin{array}{c}\text { average } \\
\text { temperature } \\
\left({ }^{\circ} \mathrm{C}\right)\end{array}$ & $\begin{array}{c}\text { rainfall } \\
(\mathrm{mm})\end{array}$ & $\begin{array}{l}\text { sunshine } \\
\text { hours (h) }\end{array}$ & $\begin{array}{c}\text { average } \\
\text { temperature } \\
\left({ }^{\circ} \mathrm{C}\right)\end{array}$ & $\begin{array}{c}\text { rainfall } \\
(\mathrm{mm})\end{array}$ & $\begin{array}{l}\text { sunshine } \\
\text { hours (h) }\end{array}$ & $\begin{array}{l}\text { average } \\
\text { temperature } \\
\left({ }^{\circ} \mathrm{C}\right)\end{array}$ & $\begin{array}{c}\text { rainfall } \\
(\mathrm{mm})\end{array}$ & $\begin{array}{l}\text { sunshine } \\
\text { hours (h) }\end{array}$ \\
\hline Bread Ketone & -0.19 & 0.38 & -0.32 & 0.08 & -0.02 & 0.58 & 0.14 & 0.13 & -0.27 \\
\hline Furfural & -0.11 & 0.28 & -0.43 & 0.15 & -0.15 & $0.619^{*}$ & 0.23 & -0.01 & -0.45 \\
\hline Furfuryl Alcohol & 0.04 & 0.06 & -0.34 & 0.31 & -0.29 & $0.716^{*}$ & 0.34 & -0.06 & -0.27 \\
\hline 5-methylfurfuryl alcohol & 0.01 & -0.12 & 0.11 & 0.15 & -0.23 & $0.655^{*}$ & 0.09 & -0.32 & 0.2 \\
\hline Benzaldehyde & 0.35 & -0.18 & -0.36 & 0.45 & -0.11 & 0.51 & 0.52 & -0.23 & -0.17 \\
\hline Benzyl alcohol & 0.18 & -0.36 & -0.09 & 0.16 & -0.43 & 0.41 & 0.21 & -0.42 & -0.04 \\
\hline Phenylacetaldehyde & 0.07 & 0.48 & $-0.624^{*}$ & 0.29 & -0.22 & -0.02 & 0.37 & 0.43 & $-0.708^{*}$ \\
\hline 2-Methylhydroquinone & 0.24 & -0.3 & 0.06 & 0.33 & $-0.611^{\star}$ & 0.46 & 0.25 & -0.32 & 0.06 \\
\hline Saffron & 0.38 & -0.46 & -0.15 & 0.39 & $-0.741^{\star *}$ & 0.36 & 0.34 & -0.38 & -0.09 \\
\hline Indole & 0.17 & -0.28 & -0.37 & 0.27 & -0.32 & $0.658^{*}$ & 0.28 & -0.32 & -0.15 \\
\hline Solanone & -0.1 & -0.46 & $0.621^{*}$ & -0.32 & -0.03 & -0.25 & -0.51 & -0.27 & $0.655^{*}$ \\
\hline$\beta$-Damascenone & -0.11 & -0.2 & -0.13 & -0.07 & -0.27 & $0.652^{*}$ & -0.08 & -0.39 & 0.06 \\
\hline Geranyl acetone & 0.25 & -0.06 & 0.2 & 0.28 & -0.24 & 0.13 & 0.22 & -0.12 & 0 \\
\hline Dihydrokiwi lactone & 0.18 & 0.03 & -0.17 & 0.42 & -0.36 & $0.739^{* *}$ & 0.51 & -0.25 & -0.31 \\
\hline $\begin{array}{c}\text { 4-(2, 6, 6-trimethyl-1, } \\
\text { 3-cyclohexadien-1-yl)-2-butanone }\end{array}$ & 0.15 & -0.37 & -0.19 & 0.24 & -0.53 & $0.723^{*}$ & 0.28 & -0.43 & -0.13 \\
\hline Iduran & -0.01 & -0.23 & -0.24 & 0.12 & -0.43 & $0.814^{* *}$ & 0.17 & -0.33 & -0.16 \\
\hline Macrostigmine A & 0.21 & -0.33 & -0.3 & 0.23 & -0.51 & 0.33 & 0.22 & -0.34 & -0.18 \\
\hline Macrostigmine B & 0.28 & -0.35 & -0.37 & 0.4 & -0.57 & $0.652^{*}$ & 0.42 & -0.26 & -0.29 \\
\hline Cedarwood alcohol & 0.19 & -0.41 & 0.26 & 0.15 & $-0.665^{\star}$ & 0.29 & -0.01 & -0.23 & 0.29 \\
\hline Benzene & 0.29 & -0.38 & -0.06 & 0.13 & -0.41 & -0.19 & 0.04 & -0.22 & 0.08 \\
\hline Macrostigmine $\mathrm{C}$ & 0.26 & -0.26 & -0.45 & 0.41 & -0.46 & $0.692^{*}$ & 0.46 & -0.28 & -0.32 \\
\hline
\end{tabular}

in Lichuan to measure the leaf length, leaf width and leaf area of the upper tobacco leaves (Figure 2), and the correlation between its agronomic characteristics and the meteorological data (Figure 3) corresponding to the three test points was analyzed. The correlation analysis results are shown in Table 4. It can be seen that the main meteorological factor affecting the upper leaf area of flue-cured tobacco is the daily average temperature during the growth period. The increase in daily average temperature is beneficial to the growth and development of the upper leaf leaves.

\section{Conclusions and Discussion}

The climatic conditions during the field growing period (May-September) in the tobacco-growing areas of our province are mainly divided into two categories. 


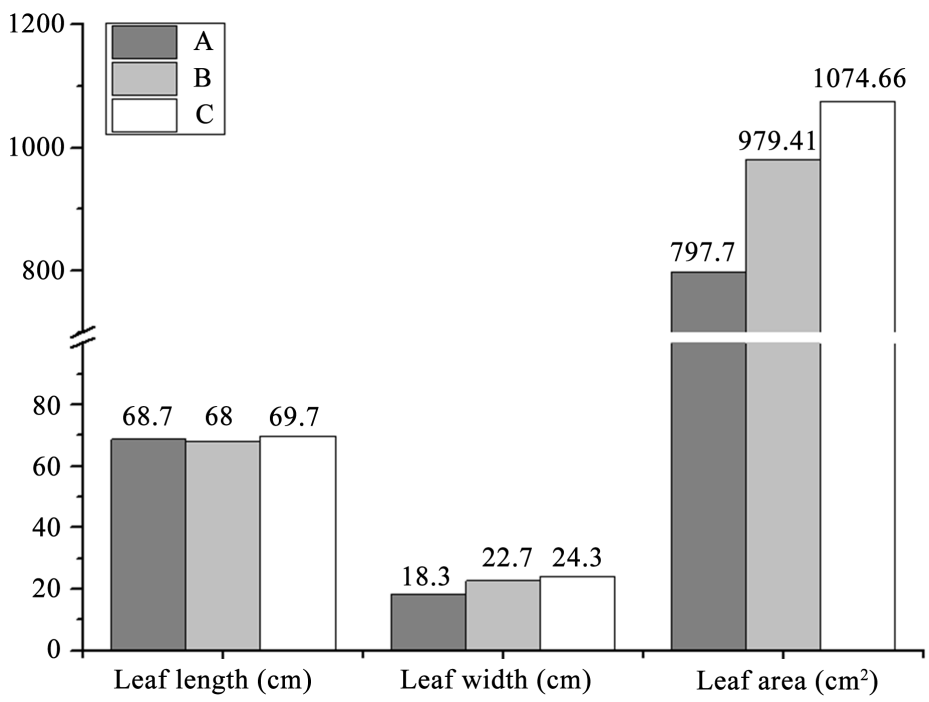

Figure 2. Average value of agronomic traits of upper leaves in three test sites in Lichuan City.

Table 4. Correlation between upper leaf agronomic traits and meteorological factor.

\begin{tabular}{|c|c|c|c|c|}
\hline & & leaf length & leaf width & leaf area \\
\hline & average temperature $\left({ }^{\circ} \mathrm{C}\right)$ & 1 & 0.35 & 0.44 \\
\hline \multirow[t]{3}{*}{ May } & rainfall $(\mathrm{mm})$ & 0.35 & 1 & 1 \\
\hline & sunshine hours $(\mathrm{h})$ & -0.1 & -0.97 & -0.94 \\
\hline & average temperature $\left({ }^{\circ} \mathrm{C}\right)$ & 0.44 & 1 & 1 \\
\hline \multirow[t]{3}{*}{ June } & rainfall $(\mathrm{mm})$ & -0.99 & -0.49 & -0.58 \\
\hline & sunshine hours (h) & 0.92 & 0.69 & 0.75 \\
\hline & average temperature $\left({ }^{\circ} \mathrm{C}\right)$ & 0.39 & $0.999^{*}$ & $0.998^{*}$ \\
\hline \multirow[t]{3}{*}{ July } & rainfall $(\mathrm{mm})$ & -0.96 & -0.07 & -0.17 \\
\hline & sunshine hours (h) & -0.91 & -0.71 & -0.77 \\
\hline & average temperature $\left({ }^{\circ} \mathrm{C}\right)$ & 0.45 & 0.99 & $1.000^{\star *}$ \\
\hline \multirow[t]{3}{*}{ August } & rainfall $(\mathrm{mm})$ & -0.88 & 0.13 & 0.03 \\
\hline & sunshine hours $(\mathrm{h})$ & 0.91 & 0.71 & 0.77 \\
\hline & average temperature $\left({ }^{\circ} \mathrm{C}\right)$ & 0.43 & 1 & $1.000^{* *}$ \\
\hline \multirow[t]{2}{*}{ September } & rainfall $(\mathrm{mm})$ & -0.98 & -0.16 & -0.26 \\
\hline & sunshine hours (h) & -0.91 & -0.71 & -0.77 \\
\hline
\end{tabular}

The first category is the tobacco-growing areas in the northwest of Hubei, including Nanzhang, Baokang, Fangxian, Zhushan, Zhuxi, Badong and Zigui; the second category is the tobacco-growing areas in the southwest of Hubei, including Enshi, Xuan'en, Lichuan and Hefeng. Precipitation in the flourishing period, the average temperature in mature period, and sunshine duration are the main differences of meteorological factors between southwestern and northwestern tobacco 


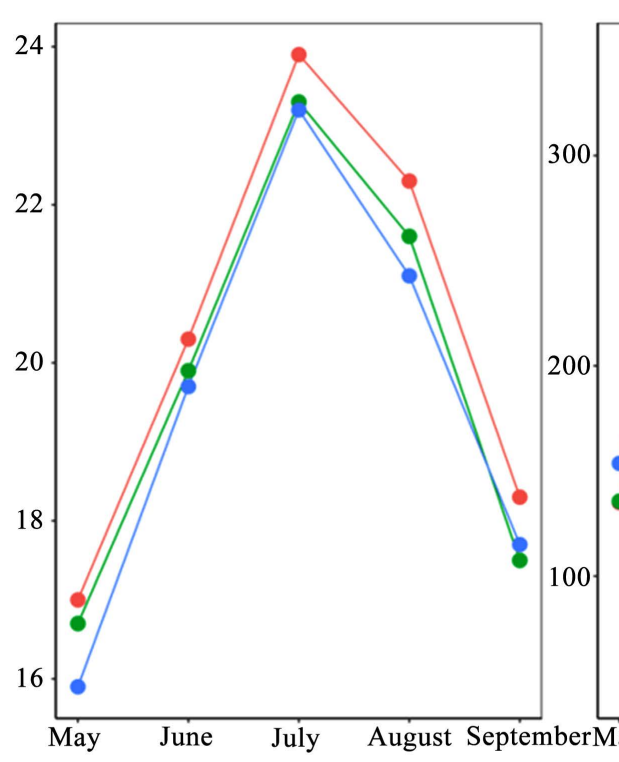

(a)

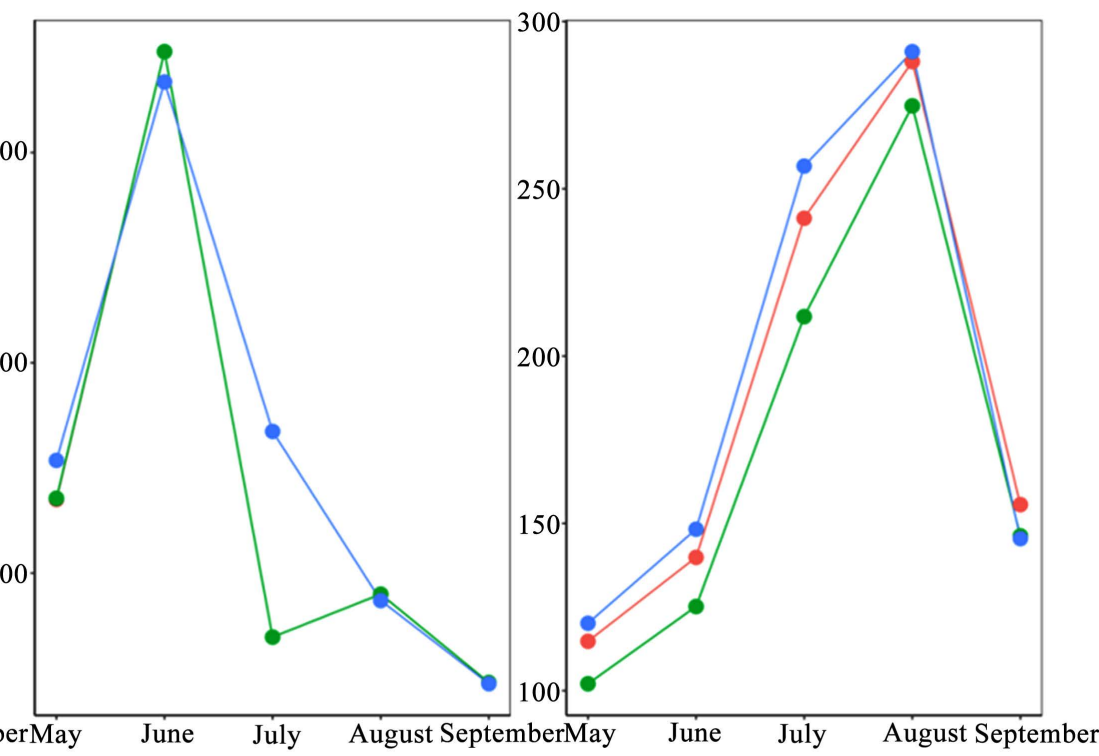

$\operatorname{taxa} \bullet \mathrm{A} \bullet \mathrm{B} \bullet \mathrm{C}$

(b) (c)

Figure 3. Meteorological data average of 3 test sites in Lichuan ((a): Average temperature during growth period of flue-cured tobacco in various regions; (b): Average rainfall during growth period of flue-cured tobacco; (c): Average sunshine duration during growth period of flue-cured tobacco in various regions).

areas of Hubei Province. The average daily average and total rainfall of southwest Hubei were $0.65^{\circ} \mathrm{C}$ higher than those of northwest Hubei, and the sunshine hours were 120.92 hours higher than those of southwest Hubei. The content of nicotine, chloride ion and total nitrogen in southwest Hubei was higher than that in northwest Hubei during the whole growth cycle, which was positively correlated with rainfall and average daily temperature. The total sugar, glycoalkaloid ratio and KCL ratio in northwestern Hubei were high and positively correlated with sunshine during the whole growing period. In terms of sensory quality, the miscellaneous gas index and irritant index in the total growth cycle in the northwest of Hubei were higher than those in the southwest of Hubei, while the aroma quality and aroma quantity were slightly lower than those in the southwest of Hubei. At the same time, the content of aroma components of tobacco leaves in southwest Hubei was generally higher than that in northwest Hubei, which indicated that the higher rainfall and daily temperature during the total growth period were more beneficial to the sensory quality of tobacco leaves. At the same time, three typical tobacco areas at different elevations were selected in Lichuan, and the agronomic status was measured. It can be seen that the higher the average daily temperature, the better the growth and development of the upper leaf.

Conventional chemical constituents, miscellaneous gases and aroma substances of tobacco leaves were correlated with light and warm water conditions. 
In previous studies, Wang Biao et al. believed that reducing sugar, total plant alkali, and total nitrogen had a higher phase with the rainfall in the flourishing period [21]. Liang Ying et al. believed that nicotine of flue-cured tobacco was negatively correlated with rainfall and positively correlated with sunshine; potassium content of flue-cured tobacco was positively correlated with average temperature and sunshine from May to September, and negatively correlated with precipitation and relative humidity [22]. According to Tian Jiale's research, gray is greatly affected by sunshine duration, while fragrance, miscellaneous gas, and combustibility are greatly affected by rainfall [23]. Research by Deng Xiaohua et al. showed that rainfall, daily average temperature, and sunshine duration are the main meteorological factors that affect the content of volatile aroma substances in flue-cured tobacco. Precipitation was significantly correlated with the total amount of dihydrokiwifolactone, trienone and furfural content of girosauria, and sunshine and average temperature also played an important role [24].

This study analyzed the correlation between the chemical composition, sensory quality and aroma composition of tobacco leaves and the average daily temperature, rainfall and sunshine hours in each month of the growing season. It can be seen that the contents of nicotine and total nitrogen in upper leaves were significantly positively correlated with the average daily temperature at maturity stage, and significantly negatively correlated with rainfall at maturity stage [8]. Climatic conditions affected the coordination of the ratio of sugar to alkali and nitrogen to alkali in upper leaves. Potassium ion content was positively correlated with the average temperature during the whole growth period [22]. This is basically similar to the previous conclusions. There was a significant positive correlation between precipitation in July and the impurity gas score in the upper leaves, and sufficient water condition in the mature stage was beneficial to reduce the impurity gas in the upper leaves [23]. There was a significant positive correlation between the number of sunshine hours in August and the content of aroma substances such as Macrostigmatrienone, 3-hydroxy- $\beta$-dihydrodamascenone, neophytadiene, dihydrokiwifruit lactone, 4-(2,6,6-trimethyl-1, 3-cyclohexadien-1-yl)2-butanone, eduran, furfural, furfuryl alcohol, 5-methylfurfuryl alcohol in the upper leaves. Therefore, the production of high-quality upper tobacco in our province should ensure better temperature and light conditions during the maturity period.

\section{Acknowledgements}

This work was supported by the key technology projects of China National Tobacco Corporation (CNTC, No. 110201902005) \& Hubei Provincial Tobacco Company (No. 027Y2021-005).

\section{Conflicts of Interest}

The authors declare no conflicts of interest regarding the publication of this paper. 


\section{References}

[1] Tang L.N., Lin, Z.B., Xie, F.B., Chen, S.H., Tian, W.X. and Huang, J.W. (2013) The Influence of Climatic Conditions on the Growth and Quality and Style Characteristics of Flue-Cured Tobacco in Fujian. China Tobacco Science, 34, 13-17.

[2] Lu, Y.H. (2007) Research Progress on the Effects of Ecological Conditions on Tobacco Leaf Quality. China Tobacco Science, 28, 43-46.

[3] Xu, Z.C., Liu, G.S., Liu, J.H., et al. (2005) Ecological Factors and Tobacco Leaf Quality Characteristics in Tongshan Tobacco Area. Acta Ecologica Sinica, 25, 1748-1753.

[4] Xu, Z.C., Huang, P.J., Su, F.Q., Li, G.X. and Wang, Y. (2005) Effects of Different Harvesting Methods on the Intrinsic Quality of Flue-Cured Tobacco Upper Leaves. Journal of Northwest Sci-Tech University of Agriculture and Forestry (Natural Science Edition), 33, 13-17.

[5] Tang, Y.J. (2004) Discussion on the Formation and Development of Characteristic Tobacco Leaves. China Tobacco Science, 25, 10-13.

[6] Tang, Y.J. (2008) Positioning of Tobacco Leaf Style Characteristics. China Tobacco Science, 29, 1-5.

[7] Shao, L., Jin, Y., Yang, Y.H., et al. (2002) The Effect of Ecological Conditions on the Yield and Quality of Different Flue-Cured Tobacco Varieties. Tobacco Science and Technology, 40-45.

[8] Peng, X.H., Yi, J.H. and Zhou, Q.M. (2009) Research Progress in the Influence of Climate on the Intrinsic Quality of Flue-Cured Tobacco. China Tobacco Science, 30, 68-72.

[9] Zhang, F.S. (2012) Analysis of the Relationship between the Quality of Flue-cured Tobacco Leaves and Climate Factors in Hezhou. Master's Thesis, Henan Agricultural University, Henan.

[10] Yang, C. (2015) The Characteristics of the Main Ecological Factors in the Tobacco Area of Chongqing and Their Effects on the Yield and Quality of Flue-Cured Tobacco. Ph.D. Thesis, Southwest University, Chongqing.

[11] Tang, Y.J. and Zhang, J.P. (2006) Preliminary Classification of Quality Ecological Types of Shanghai's Main Flue-Cured Tobacco Production Bases. China Tobacco Science, 27, 1-5.

[12] Li, Y.Y., Ding, W., Li, C.Y., et al. (2007) Analysis of Ecological Conditions and Flue-Cured Tobacco Quality in Guizhou Tobacco Areas. Journal of Safety and Environment, 7, 96-100.

[13] Zhang, X.Q., Wang, J., Chen, Y.M., et al. (2011) Analysis of Main Climatic Factors and Quality Characteristics of Flue-Cured Tobacco in Nanxiong Tobacco Area in Guangdong. Northwest Agricultural Journal, 20, 75-80.

[14] Cao, J.L., Cheng, J.Q., Li, Y.P., Wu, C.L. and Zhang, J.J. (2020) Changes in the Conventional Chemical Components of Flue-Cured Tobacco in Hubei Tobacco Areas in the Past 10 Years. Hubei Agricultural Sciences, 59, 107-110.

[15] Wang, J., Ding, X.D., Luo, J., Wang, X.B., Wang, Z.R. and Chen, Z.P. (2016) The Relationship between Climatic Conditions in Nanxiong Tobacco Area and the Composition of Tobacco Leaves and Main Chemical Components. Journal of South China Agricultural University, 37, 54-61.

[16] Hu, Z.S., Long, W., Tan, J., et al. (2012) Evaluation and Analysis of Eco-Climatic Factors of Flue-Cured Tobacco in Chuxiong Tobacco Region. China Tobacco Science, 33, 63-68. 
[17] Zhou, M.K., Li, G.C., Zhang, C.W., et al. (2012) The Impact of Climatic Conditions on the Yield and Quality of Flue-Cured Tobacco in Dali Prefecture. Anhui Agricultural Science, 3470-3473.

[18] Yu, J.F., Zheng, F.W., Qing, X.T., Zhang, L.M. and Liu, W.X. (2018) Climatic Characteristics of Xiangxi Tobacco Areas and Their Effects on the Appearance Quality and Physical Characteristics of Tobacco Leaves. Journal of Gansu Agricultural University, 53, 43-51+57.

[19] Dong, X.C., Qin, T.W. and Liu, L.M. (2008) Analysis of Climatic Factors and Flue-Cured Tobacco Quality Characteristics in Xingshan Tobacco Area in Hubei Province. Journal of Anhui Agricultural Sciences, 36, 9575-9579+9636.

[20] Liu, C.K. (2008) Comprehensive Evaluation of Climate Factors and Flue-Cured Tobacco Quality in Hubei Enshi Tobacco Area. Master's Thesis, Henan Agricultural University, Henan.

[21] Wang, B. and Li, T.F. (2005) Correlation Analysis of Meteorological Factors and Chemical Components of Tobacco Leaves. Journal of Yunnan Agricultural University, 20, 742-745

[22] Liang, Y., Ma, S.Q., Wang, X.T. and Liu, J.J. (2020) The Relationship between the Nicotine and Potassium Content of Jilin Flue-Cured Tobacco and Meteorological Conditions. Meteorological Disaster Prevention, 27, 30-35.

[23] Tian, J.L. (2013) Study on the Influence of Regional Climate on Tobacco Quality. Master's Thesis, Southwest University, Chongqing.

[24] Deng, X.H., Xie, P.F., Peng, X.H., Yi, J.H., Zhou, J.H., Zhou, Q.M., PU, W.X. and Dai, Y.G. (2010) Effects of Soil and Climate on the Contents of Some Neutral Volatile Aroma Substances in Flue-Cured Tobacco in Hunan Province. Chinese journal of Applied Ecology, 21, 2063-2071. 